\title{
PATTERN OF DEEP NECK SPACE INFECTIONS AT A TERTIARY HOSPITAL, KATHMANDU, NEPAL
}

\author{
Maharjan S, Joshi RR, Rijal AS, Dhungana A, Shrestha KK
}

Department of Otorhinolaryngology \& Head and Neck Surgery, Nepal Medical College Teaching Hospital, Attarkhel, Gokarneshwor-8, Kathmandu, Nepal

\begin{abstract}
Deep neck space infection is characterized by infections of the deep neck space either in the form of abscess or cellulitis. Common infective conditions like aero-digestive tract infections like tonsillitis, pharyngitis and dental infections can lead to infection of the deep neck spaces. This can prove fatal in the form of acute respiratory obstruction, descending mediastinitis and septic shock. This was a descriptive cross-sectional study conducted in Department of Otorhinolaryngology in Nepal Medical College from July 2017 to June 2019. All the patients diagnosed as deep neck abscess were enrolled in the study and pus was collected and sent for gram stain and culture and sensitivity. Out of 87 patients, 50 were females and 37 males. The mean age was 24.2 years. Peritonsillar abscess was the commonest space involved followed by submandibular abscess and Ludwig's angina (36.8\%,24.1\% and 11.5\%). Upper respiratory tract infections (32.2\%) and dental caries (27.6\%) were the commonest source of infection. Empyema thoracis was seen as a complication in a patient of Ludwig's angina. Growth in the sample accounted for $33.3 \%$. The commonest organism found was Coagulase negative Staphylococcus (10.3\%), followed by Mycobacterium tuberculosis (6.9\%), Staphylococcus aureus (4.6\%), Enterococcus species (3.4\%) and methicillin-resistant S. aureus (3.4\%) respectively. The growth between the culture with or without previous antibiotic exposure were statistically significant (p-value-0.04) which suggest that inadvertent use of antibiotics lead to difficulty in identifying causative organism. Deep neck abscess is a dreadful condition, therefore proper knowledge, early detection and timely intervention of the disease can prevent complications.
\end{abstract}

\section{KEYWORDS}

Deep neck space, infection, microorganisms.

\section{CORRESPONDING AUTHOR}

Dr. Shova Maharjan

Lecturer,

Department of Otorhinolaryngology \& Head and Neck Surgery, Nepal Medical College Teaching Hospital, Attarkhel, Gokarneshwor-8, Kathmandu, Nepal.

Email: mahajanshova@gmail.com

Orcid ID: 0000-0003-1710-3287

DOI: https://doi.org/10.3126/nmcj.v22i1-2.30032 


\section{INTRODUCTION}

Deep neck space infection (DNSI) is characterized by infection in the potential spaces and fascial planes of the neck either with abscess formation or cellulitis. ${ }^{1}$ Any bacterial infection originating from the upper aerodigestive tract and head and neck region like tonsillitis, dental caries, sialoadenitis, vestibulitis, otitis externa, otitis media can be complicated with inflammation and suppuration of deep neck spaces. ${ }^{2}$ The commonest cause is dental infection followed by suppurative lymphadenitis. ${ }^{3-6}$ In most instances, these conditions resolve without surgical intervention. However, at times it can lead to life threatening conditions like acute airway obstruction, jugular venous thrombosis, pneumonia, descending mediastinitis, pericarditis and empyema thoracis despite widespread use of antibiotics. ${ }^{7}$ DNSI is usually multibacterial in etiology. Streptococcus viridans is the commonest organism isolated followed by Staphylococcus spp. and Klebsiella pnuemoniae. ${ }^{8}$ Submandibular space is the commonest space to be affected. ${ }^{9}$ The presence of co-morbid conditions like diabetes mellitus, fistulas, cysts, HIV infection and immunosuppression attribute to formation of abscess. Lack of health education, unawareness of health, unreachable health system, lower socio-economic conditions and improper dispensation of drugs contribute to late presentation with complications like necrotizing fasciitis, respiratory distress and septic shock. Therefore, detail knowledge of the disease is necessary for early detection, proper management and prevention of complications. This study aimed to see the patterns of DNSI in terms of demography, frequency of involvement of different neck spaces and the commonest causative organisms.

\section{MATERIALS AND METHODS}

This was a descriptive cross-sectional study done in the Department of Otorhinolaryngology and Head \& Neck Surgery in Nepal Medical College Teaching Hospital from July 2017 to June 2019. Ethical clearance was taken from Instituitional Review Committee prior to the study. Sample size was calculated to be 87 . All the patients with clinical as well as radiological diagnosis of deep neck space infection were included. Post-surgical abscesses and abscesses in malignancy were excluded. The pus was collected under aseptic condition either by aspiration or by incision and drainage. Patient was given general anaesthesia whenever necessary. The sample was sent for gram staining and culture and sensitivity. Zeihl Neelson staining was done in suspicious cases of tuberculosis. Patient was started with empirical antibiotic therapy of ceftriaxone and if required, later changed according to the sensitivity report. Statistical analysis was done using SPSS 17 . Chisquare test was used and p-value $<0.05$ was considered significant.

\section{RESULTS}

Out of 87 patients, $57.5 \%$ were female and $42.5 \%$ were male. Their ages ranged from 1 to 82 years with a mean age of 24.2 years. Most patients were between $20-29$ years of age accounting for $28.7 \%$ of all cases.

\begin{tabular}{|lcc|}
\hline \multicolumn{3}{|c}{ Table 1: Age distribution } \\
\hline Age group (years) & $\mathbf{n}$ & $\mathbf{\%}$ \\
\hline $0-9$ & 19 & 21.8 \\
$10-19$ & 17 & 19.5 \\
$20-29$ & 25 & 28.7 \\
$30-39$ & 9 & 10.3 \\
$40-49$ & 10 & 11.5 \\
$50-59$ & 2 & 2.3 \\
$60-69$ & 3 & 3.4 \\
$70-79$ & 1 & 1.1 \\
$80-89$ & 1 & 1.1 \\
\hline Total & $\mathbf{8 7}$ & $\mathbf{1 0 0 . 0}$ \\
\hline
\end{tabular}

The most common deep neck space involved was peritonsillar space $(36.8 \%)$ followed by submandibular space $(24.1 \%)$ and Ludwig's angina (11.5\%). Majority of the patients needed surgical intervention accounting for 95.4\%.

Table 2: Frequency of different deep neck abscesses

\begin{tabular}{|lcc|} 
Types & n & \% \\
\hline Peritonsillar abscess & 32 & 36.8 \\
Submandibular abscess & 21 & 24.1 \\
Ludwig's angina & 10 & 11.5 \\
Posterior neck abscess & 9 & 10.3 \\
Infra-auricular abscess & 5 & 5.7 \\
Parotid abscess & 3 & 3.4 \\
Submental abscess & 2 & 2.3 \\
Submandibular and peripa- & 2 & 2.3 \\
rotid abscess & & \\
Submandibular and submen- & 1 & 1.1 \\
tal abscess & 1 & 1.1 \\
Periparotid abscess & 1 & 1.1 \\
Postauricular abscess & $\mathbf{8 7}$ & $\mathbf{1 0 0 . 0}$ \\
\hline Total &
\end{tabular}


Most of the abscesses had upper respiratory tract infections $(28 ; 32.2 \%)$ and dental caries (24; $27.6 \%)$ as a predisposing factors. Skin infections and salivary gland infections were among others as seen in Table 3.

Table 3: Presence of predisposing factors

\begin{tabular}{|lcc|} 
Predisposing factors & $\mathbf{n}$ & $\mathbf{\%}$ \\
\hline Unknown & 29 & 33.3 \\
URTI & 28 & 32.2 \\
Dental caries & 24 & 27.6 \\
Skin infection & 2 & 2.3 \\
Parotitis & 1 & 1.1 \\
Preauricular sinus & 1 & 1.1 \\
Sialolithiasis & 1 & 1.1 \\
Trauma & 1 & 1.1 \\
\hline Total & $\mathbf{8 7}$ & $\mathbf{1 0 0 . 0}$ \\
\hline
\end{tabular}

Growth was seen in only 29 of 87 samples (33.3\%). The most common organism found was Coagulase-negative Staphylococcus (CoNS) which was seen in 9 samples (10.3\%). The second most common organism was $M$. tuberculosis, which was detected from clinically suspected cases of tuberculosis by Ziehl Neelson staining and was seen in 6 samples $(6.9 \%)$. S. aureus was seen in 4 samples (4.6\%) followed by Enterococcus spp. and methicillin-resistant $S$. aureus (MRSA), which was $3(3.4 \%)$ each.

\begin{tabular}{|lcc|}
\hline \multicolumn{3}{|c|}{ Table 4: Growth Pattern } \\
\hline Organism & n & \% \\
\hline No growth & 58 & 66.7 \\
CoNS & 9 & 10.3 \\
M. tuberculosis & 6 & 6.9 \\
S. aureus & 4 & 4.6 \\
Enterococcus spp & 3 & 3.4 \\
MRSA & 3 & 3.4 \\
Normal flora & 2 & 2.2 \\
Proteus mirabilis & 1 & 1.1 \\
TB with CoNS & 1 & 1.1 \\
\hline Total & $\mathbf{8 7}$ & $\mathbf{1 0 0 . 0}$ \\
\hline
\end{tabular}

Culture was negative in 58 samples (66.7\%). This could be due to rampant use of improper antibiotic before seeking the treatment in the hospital which is a very common practice in our part of the world. The growth of an organism was also analyzed in relation with antibiotic usage before seeking treatment which was statistically significant in this study (p-value-0.04) (Table-5).

\begin{tabular}{|c|c|c|c|}
\hline \multirow{2}{*}{$\begin{array}{l}\text { Previous antibiotic } \\
\text { use }\end{array}$} & \multicolumn{2}{|c|}{ Growth } & \multirow{2}{*}{ Total } \\
\hline & No & Yes & \\
\hline No & 20 & 16 & 36 \\
\hline Yes & 39 & 12 & 51 \\
\hline Total & 59 & 28 & 87 \\
\hline
\end{tabular}

p-value: 0.04 (Chi square test)

\section{DISCUSSION}

Deep neck abscess is a serious condition which can lead to severe complications and even death. It has no age or sex predilection but its incidence is estimated to be 9-12/100,000/year with increasing occurrence in children. ${ }^{16,17}$

Our study has shown that the prevalence is higher in third decade of life with mean age of 24.2 years. Similar findings were reported by Brito et $a l^{10}$ and Eftekharian et $a l^{18}$ which showed mean age of 28.1 and 28.2 years respectively. However prevalence is higher in older patients in a study done by Huang et al. ${ }^{19}$ In a study by Kataria et al, ${ }^{5}$ more of the patients were in the third and fourth decades of life.

Our study has shown female preponderance in contrary to other studies.,313,20,21 This might be due to carelessness and late presentation of the disease.

Peritonsillar space $(36.8 \%)$ was the most common space involved in this study followed by submandibular space (24.1\%) and Ludwig's angina $(11.5 \%)$. The spaces involved in other studies were also similar but in different ratios. Ludwig's angina was the commonest abscess (28.94\%), followed by peritonsillar abscess (23.68\%) and submandibular abscess (18.42\%) which was stated by Kataria et $a l^{5}$ and Varghese et al. ${ }^{22}$ Similarly, peritonsillar abscess and submandibular abscesses were the second and the third most common abscess in studies done by Parishchar et al and Stalfors et al. . $^{3,9}$

Most of the patients needed surgical intervention except four patients who did well with intravenous antibiotics alone which was similar to the study done by Daramola et $a l^{1}$ and Wang et $a l^{4}$ and Eftekharian et al. ${ }^{18}$ In contrast, Boscolo-Rizzo et al stated that almost two-third of the patients in his study were treated with antibiotics alone..$^{23}$

One of the patient developed a complication whose illness progressed from Ludwig's angina, multiple abscesses in the neck to empyema thoracic. Brito et al also found that descending mediastinitis was the commonest complication in multispace neck abscesses. ${ }^{10}$ 
Tracheostomy was done in the cases of Ludwig's angina in our study to alleviate the upper airway obstruction like in the studies by Brito et al and Har- El et al. ${ }^{10,24}$

Most of the abscesses had upper respiratory tract infection (32.2\%) and dental pathology (27.6\%) as the origin of abscess in our study whereas dental focus was higher (37\%) than upper aero-digestive tract infection (20\%) in a study done by Coelho et $a l^{25}$ and Sennes et al. ${ }^{26}$

Diabetes mellitus was seen as an associated systemic disorder in our study which was similar to the other studies. ${ }^{3,19}$ Whereas cardiopulmonary diseases were more prevalent as a co-morbid condition in a study done by Kauffmann et al. ${ }^{2}$

The microbiology of the deep neck abscess varies with the space involved. Brook et al ${ }^{27}$ and Dodds et al ${ }^{28}$ stated that the spaces near oropharynx often yield normal flora from its indigenous area, where as the space that is distant from the oropharynx tend to grow organism indigenous to the skin. Most of our culture yielded CoNS however in the study conducted by Jayagandhi et $a l, K$. pnuemoniae was the commonest organism followed by Staphylococcus spp. ${ }^{21}$ In another study done by Coticchia et al, S. aureus and Group A Streptococcus were found to be the common organisms. ${ }^{29}$

Sixty-six percent of the sample did not yield any microorganism which might be due to random prescription of higher generation antibiotics before proper diagnosis and culture and sensitivity of the pus.

In conclusion, deep neck abscess is a dreaded disease due to its location and complication. It can occur in any age group and gender. Peritonsillar abscess is found to be the commonest space of involvement. The commonest isolate was CoNS. Upper respiratory tract infection was the most common predisposing factor for deep neck abscess. The antibiotic usage before presentation was found to have negative effect on the growth of organism and subsequent treatment.

\section{REFERENCES}

1. Wang LF, Kuo WR, Tsai SM, Huang KJ. Characterizations of life-threatening deep cervical space infections: a review of one hundred ninetysix cases. Am J Otolaryngol 2003; 24: 111-7.

2. Durazzo MD, Pinto FR, Loures MS et al. Deep neck spaces and their significance in cervical infections. Rev Assoc Med Bras 1997; 43: 119-26.

3. Parhiscar A, Har-El G. Deep neck abscess: a retrospective review of 210 cases. Ann Otol Rhinol Laryngol 2001; 110: 1051-4.

4. Daramola OO, Flanagan CE, Maisel RH, and Odland RM. Diagnosis and treatment of deep neck space abscesses. Otolaryngol Head Neck Surg 2009; 141: 123-30.

5. Kataria G, Saxena A, Bhagat S, Singh B, Kaur M, Kaur G. Deep Neck Space Infections: A Study of 76 Cases. Iran J Otorhinolaryngol 2015; 27: 293-9.

6. Larawin V, Naipao J, Dubey SP. Head and neck space infections. Otolaryngol Head Neck Surg 2006; 135: 889-93.

7. Ridder GJ, Technau-Ihling K, Sander A, Boedeker CC. Spectrum and management of deep neck space infections: an 8-year experience of 234 cases. Otolaryngol Head Neck Surg 2005; 133: 709-14.

8. Shah A, Ramola V, Nautiyal V. Aerobic microbiology and culture sensitivity of head and neck space infection of odontogenic origin. Nat'l J Maxillofacial Surg 2016; 7: 56-61.

9. Stalfors J, Adielsson A, Ebenfelt A, Nethander G, Westin T. Deep neck space infections remain a surgical challenge. A study of 72 patients. Acta Otolaryngol 2004; 124: 1191-6.
10. Brito TP, Hazboun IM, Fernandes FL et al. Deep neck abscesses: study of 101 cases. Braz J Otorhinolaryngol 2017; 83: 341-8.

11. Agarwal AKS, Sethi A, Mrig D, Chopra S. Role of socioeconomic factors in deep neck abscess: A prospective study of 120 patients. British J Oral Maxillofacial Surg 2007; 45: 553-5.

12. Sakaguchi M, Sato S, Ishiyama T, Katsuno S, Taguchi K. Characterization and management of deep neck infections. Int'l J Oral Maxillofacial Surg 1997; 26: 131-4.

13. Meher R, Jain A, Sabharwal A, Gupta B, Singh I, Agarwal AK. Deep neck abscess: a prospective study of 54 cases. J Laryngol Otol 2005; 119: 299302.

14. Chang L, Chi H, Chiu NC, Huang FY, Lee KS. Deep neck infections in different age groups of children. J Microbiol Immunol Infect 2010; 43: 47-52.

15. Kim DH, Choi HG, Kim JH, Kim HS, Park B. Characteristics of Microbiology of Deep Neck Abscess. Korean J Otorhinolaryngol-Head Neck Surg 2014; 57: 379-83.

16. Gorjón PS, Pérez PB, Martín ACM, Dios JCP, Alonso SE, Cabanillas MIC. Infecciones cervicales profundas. Revisión de 286 casos. Acta Otorrinolaringol Esp 2012; 63: 31-41.

17. Adil E, Tarshish Y, Roberson D, Jang J, Licameli G, Kenna M. A review of complications of odontogenic infections. Nat'l J Maxillofac Surg 2015; 6: 136-43.

18. Eftekharian A, Roozbahany NA, Vaezeafshar R, Narimani N. Deep neck infections: a retrospective 
review of 112 cases. Eur Arch Otorhinolaryngol 2009; 266: 273-7.

19. Huang TT, Liu TC, Chen PR, Tseng FY, Yeh TH, Chen YS. Deep neck infection: analysis of 185 cases. Head Neck 2004; 26: 854-60.

20. Sethi DS, Stanley RE. Deep neck abscesses: Challenging trends. J laryngol Otol 1994; 108: 13843.

21. Jayagandhi S, Cheruvu SC, Maninaran V, Mohanty S. Deep Neck Space Infection: Study of 52 Cases. Indian J Otolaryngol Head Neck Surg. DOI: https:// doi.org/10.1007/s12070-019-01592-3

22. Varghese L, Mathews SS, Antony J, Prakash JAJ VR. Deep head and neck infections: outcome following empirical therapy with early generation antibiotics. Trop Doct 2018; 48: 179-82. DOI: 10.1177/0049475518774472. Epub 2018 May 14.

23. Boscolo-Rizzo P, Stellin M, Muzzi E, et al. Deep neck infections: a study of 365 cases highlighting recommendations for management and treatment. Eur Arch Otorhinolaryngol 2012; 269: 1241-9.

24. Har-El G, Aroesty JH, Shaha A, Lucente FE. Changing trends in deep neck abscess. A retrospective study of 110 patients. Oral Surg Oral Med Oral Pathol 1994; 77: 446-50.

25. Coelho MS, Ramos G, Prestes LC, Soccol A, Oliveira MSB, Lobo P. Deep neck infections- classification in levels of severity. Int'l Arch Otorhinolaryngol 2009; 13: $184-8$.

26. Sennes LU, Imamura R, Júnior FVA, Frizzarini R, Tsuji DH. Infeccões dos espac,os cervicais: estudo prospective de 57 casos. Rev Bras Otorrinolaringol 2002; 68: 388-93.

27. Brook I. Microbiology of abscesses of the head and neck in children. Ann Otol Rhinol Laryngol 1987; 96:429-33.

28. Dodds B, Maniglia AJ. Peritonsillar and neck abscesses in the pediatric age group. Laryngoscope 1988; 98: 956-9.

29. Coticchia JM, Getnick GS, Yun RD, Arnold JE. Age, Site-, and time-specific differences in pediatric deep neck abscesses. Arch Otolaryngol Head Neck Surg 2004; 130: 201-7. 